Bartın Üniversitesi

Eğitim Fakültesi Dergisi

Cilt 6, Sayı 3, s. 1409-1419, Ekim 2017

BARTIN - TÜRKIYE

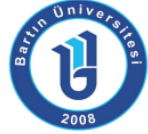

ISSN: 1308-7177
Bartin University

Journal of Faculty of Education

Volume 6, Issue 3, p. 1409-1419, October 2017

BARTIN - TURKEY

Doi: 10.14686/buefad.346862

\title{
Sosyal Bilgiler Öğretmen Adaylarının Sözlü Tarih Çalışmalarına ilişkin Tutumları
}

Ayşegül TURAL, Yrd. Doç. Dr., Bartın Üniversitesi Eğitim Fakültesi, atural@bartin.edu.tr

Öz: Bireylerin yaşadıkları topluma uyumu konusunda, geçmiş yaşantıları ve tecrübeleri önemlidir. Toplumların sahip olduğu değerler, sözlü kültür ve kültürel miras öğelerinin aktarımı aşamasında eğitimin yeri ve önemi büyüktür. Bu bakımdan sözlü tarih son yıllarda eğitim ortamlarında farklı bir yöntem olarak dikkat çekmektedir. Sözlü tarihten; tarihsel konuların, olayların ve yaşantıların belgelere, kanıtlara, geçmiş tecrübelere dayanarak günümüze aktarılmasında yararlanılmaktadır. Bu araştırmanın amacı Sosyal bilgiler öğretmen adaylarının sözlü tarih çalışmalarına ilişkin tutumlarını ortaya koymaktır. Bu amaçla araştırmada, 'Akbaba ve Kııcan (2012) tarafından geliştirilen, Sözlü Tarih Çalışmalarına Yönelik Tutum Ölçeği' ile veriler toplanmıştır. Araştırma sonucunda Sosyal bilgiler öğretmen adaylarının sözlü tarih çalışmalarına yönelik tutumlarında tarihsel aktarım boyutunda cinsiyete göre anlamlı bir farklılık bulunmuştur. Tarihi roman okuma değişkeni açısından da kitap okuyanlar lehine anlamlı farklılık olduğu görülmüştür.

Anahtar Sözcükler: Sosyal bilgiler, sözlü tarih, tutum.

\section{Prospective Social Studies Teachers' Attitude towards Oral History Studies}

\begin{abstract}
Individuals' lives in past and experiences are important for their compliance to society. Place and importance of education is crucial to transmit values, oral culture and cultural heritage elements that societies have. For that reason; oral history gets attracts in education environments as a different method in last years. Oral history is benefitted in fields of transmission of historical events and topics, livings to today by documents, proofs and past experiences. Aim of this research is to put forward attitudes of social studies teacher candidates regarding oral history studies. By this aim, data is collected with Attitude Scale regarding Oral History Studies developed by Akbaba and KIlcan (2012). At the end of research; it is found that there is significant difference between attitudes of social studies teacher candidates regarding oral history studies at the historical transmission dimension depends on sex. It is seen that there is an important difference in sense of historical novel reading parameter in countenance of people who read book.
\end{abstract}

Key Words: Social studies, oral history, attitude. 


\section{GíRiş}

Sosyal bilgiler dersi ile öğrencilere kazandırılması gereken kazanımlar, beceriler incelendiğinde temelde bu amaçların hemen hemen hepsinin toplumun kültürel birikimine, vurgu yaptığı, dolayısıyla bu amaçlara ulaşabilmek için sosyal bilgiler dersinde kültürel ögelerden yararlanmanın gerekli olduğu söylenebilmektedir (Deveci, 2009, 2). Toplumun kültür öğeleri denildiğinde somut olmayan kültürel miras unsurları da öne çıkmaktadır. Toplumların somut olmayan kültürel miras öğeleri içinde tarihsel unsurlar da bulunmaktadır. Geçmişten günümüze insana ve yaşama dair her şey tarihsel aktarım yoluyla ulaşmıştır. Bu tarihsel aktarım içinde sözlü tarihin rolü büyüktür. Sözlü tarih kültür aktarımı yaparken, birçok farklı disiplinin çalışma alanından yararlanmaktadır. Özellikle sözlü edebiyat ürünlerinden destanlar, masallar, halk hikâyeleri, menkıbeler ve mesneviler sözlü tarihin çalışma alanı içinde yakın ilişkili türler olarak sıralanabilmektedir (Ulusoy, 2011, 160).

Sözlü tarihin dünyadaki gelişimi, köklü bir tarihe dayanmakla birlikte, 20. yy içinde tarihçiler, sözlü tarihin anlamını ve önemini keşfetmişlerdir. Tarihçilerin, sözlü tarihin içinde olan sözlü, yerel ve sessiz tarafları hedef almasıyla günümüzdeki sözlü tarih algısı oluşmaya başlamıştır (Çaykent, 2015, 133). Sözlü tarih, tarihin kendisi kadar eski olmakla birlikte, eğitim süreci içinde belirli dönemlerde alternatif bir yöntem olarak öne çıkmaktadır. Sözlü tarihin kullanılışında ses kaydı ile görüşmeyi kaydetmek ve modern tekniklerden faydalanmak özellikle günümüzde bu yöntemin radikal etkilerini arttırmak açısından dikkatle vurgulanmaktadır (Thompson ve Bornat, 2017, 23). Sözlü tarih, konuşan belgeler ve kanıtlar üzerine kurulu bir yöntemdir. Tarihin içindeki, konuşmalar, şarkılar, görüşmeler, tartışmalar gibi tüm sözlü dökümanlar, sözlü tarihin amacına hizmet etmektedir (Hoopes, 1979, 5). Bu açıdan sözlü tarih, tarihe yakından tanıklık etmeye yardımcı olabilme imkanı sunmaktadır (Thompson ve Bornat, 2017, 11). Tarihe bu yakından tanıklık ile sözlü tarih, tarihi konuların, yaşayan tarih aktörlerinin (tecrübelerini aktaranlar) ilettikleri bilgilerin işlenmesiyle ortaya çıkan üründür denilebilmektedir (Kabapınar, 2016, 289; Demircioğlu, 2005, 311).

Tarihe alışılmışın dışında daha farklı bakan zihinlerin ürünü olarak ifade edilen sözlü tarih (Tokmak, 2016, 84), kültürel mirasın aktarımında önemli bir yöntemdir (Çengelci, 2012, 189). Sözlü tarih; konusu ve içeriğiyle, geçmişle bugünü ilişkilendirerek anlamaya yardımcı olmaktadır. Yaşantıların ve deneyimlerin sözlü tarih içinde ele alınmasında görüşmelerin büyük önemi vardır (Yow, 2015, 26). Bu görüşmeler ile yaşanmışlıkları anlamlandırırken, bireylerin tarih bilinci, tarihsel empatileri ve değişim süreklilik algıları da gelişmektedir. Kültürel aktarım aracı olarak sözlü tarih çalışırken, geçmişten beri korunagelen değerler, alışkanlıklar ve günlük hayatla ilişkili durumlar da açığa çıkmaktadır (Kabapınar, 2016, 290). Geçmiş yaşantılar, örf adetler, alışkanlıklar, aile hayatı, bayramlar, düğünler ve eğitim gibi önemli olaylar, özel günler gibi konular sözlü tarihin temel konuları arasında yer almaktadır. Bu bakımdan sözlü tarih; insanı konu edinen ve toplumsal yaşamın içinde olan bir alandır. Sözlü tarihin içindeki bu konuların ortak özelliği ise sıradan insanların yaşantısına dokunması (Öztürk, 2010, 14), değişim ve sürekliliği, geçmiş-bugün ve yarının arasında bağ kurarken insan ilişkilerinden faydalanması olarak ifade edilmektedir (Kabapınar ve İncegül, 2016, 75).

Sözlü tarih tanıklığı, geçmiş yaşantılara ve olaylara ilişkin belgeleri anlaşılabilir kılan bir bilgi türü olarak ifade edilmektedir. Geçmişe ilişkin yaşantılar ve belgeler ile, belge yok ise insanların kanıtları ve aktarımı ile anlaşılabilir hale dönüşmektedir (Yow, 2015, 12). Çünkü sadece belgelere dayanarak tarihi anlamaya çalışmak bazen yetersiz kalmaktadır. Bu açıdan tarihsel belgelerin yanı sıra kişilerin hayat öykülerini, tecrübelerini, hatıralarını dinlemek, bilgi ve yaşanmışıkların geleceğe aktarımında sözlü tarihe ilişkin boşlukları doldurmaktadır (Küpüç, 2014, 1). Bu bakımdan sözlü tarihçiler için, süreç içinde yaşça daha olgun, deneyim ve 
yaşanmışlıkları fazlaca olan insanlarla çalışmak, genç yetişkinler ile bu sürece dahil olmaktan daha yararlı bulunmaktadır (Yow, 2015, 44).

Sözlü tarih, kişilerin yaşanmışıklarını, hafızalarında korudukları aktif bir süreçtir (Ritchie, 2015, 16). Bu aktif ve dinamik süreç, hem okul içi hem de okul dışında, birey olmayı önemserken, proje çalışmaları ve etkinlikler ile grup çalışmalarını da desteklemektedir (Thompson ve Bornat, 2017, 8). Özünde sözlü tarihin materyalleri, 'hikayeler'dir. Eğitimde hikayeler yoluyla yaşanmışlıkların aktarımında etkili yöntemlerden biri 'drama'nın kullanılmasıdır. Geçmiş tecrübelerin ve olayların drama ile aktarımı sözlü tarihin derinliğini artırabilmektedir (Thompson ve Bornat, 2017, 14). Ancak sözlü tarih çalışmalarının başarılı bir şekilde gerçekleştirilmesi için öncelikle iyi bir süreç planlaması gerekmektedir. Bu süreçte rehber olan eğitimciden, sözlü tarih çalışma konu ve alanını, sınırlarını iyi belirlemesi, öğrencilerin süreç sonunda kazanması beklenilen bilgi ve becerileri açıkça ortaya koyabilmesi, çalışma grubunu seçmesi, okul içi - okul dışı etkinlikler için gerekli izin ve düzenlemeleri tamamlaması, süreç sonundaki ölçme değerlendirme boyutu gibi bir dizi hazırlığı sürdürmesi beklenmektedir (Demircioğlu, 2005, 311-312). Sözlü tarihin derslerde kullanılması ile farklı bir bakış açısı gelişip, dersin içeriği zenginleşeceğinden, normalde görülemeyen ayrıntılar görülebilir hale dönüşmektedir. Böylece derslerin öğrenciler için daha nitelikli, zevkli ve katılımcılığı destekler hale dönüştürülebileceği vurgulanmaktadır (Avcı Akçalı ve Aslan, 2012, 677; Akbaba ve Kılcan, 2014, 750). Sözlü tarih etkinlikleri ile yürütülen dersler öğrencilere daha canlı, zengin ve dinamik bir öğrenme ortamı sunduğundan etkili bir öğrenme gerçekleşebilmektedir.

Sözlü tarih, hem tarihin diğer disiplinlerle olan ilişkisiyle, hem de geleneksel bilginin sözlü iletimi ile yakından ilgilenmektedir (Ritchie, 2015, 24). Tarihin bir alanı olarak, yazılı bilgi ve belgeleri ilk elden incelerken, belleğe dayalı hatıraları, sözlü gelenekleri de ses kaydı gibi tekniklerle ürüne dönüştüren sözlü tarih, disipinler arası bir çalışma alanı ve tarihsel yöntem olarak görülmektedir (Özer, 2012, 36). Bu yöntem, bireylerin ait oldukları kültüre ilişkin geçmişten bu yana süregelen alışkanlıklarını, düşüncelerini yakından tanımak ve tarihe tanıklık ederken bireylerin belleklerindeki yaşanmışlıklarının iletimi sırasında, alışkanlıklarında gerekirse değişiklikler yapmak için de kullanılabilmektedir (Yow, 2015, 25; Portelli, 2009, 26). Bu yönüyle sözlü tarihin öğretici yapısı açığa çıkmaktadır. Çünkü sözlü tarih, yalnızca kişilerin hatıralarına dokunmakla, yaşanmışlıklarını incelemekle kalmaz aynı zamanda bireylerin gelişimine de destek olur.

Yapısal olarak insanlara odaklanan bir tarih türü olarak ifade edilen sözlü tarihin odağında, sadece yaşadığı dönemde iz bırakmış liderler değil, günlük yaşamın içindeki sıradan insanlar, olaylar da bulunmaktadır. Sosyal bilgiler dersi de insan ve topluma ilişkin içeriği ile sözlü tarihin etkinliklerine uygun bir ortam sunmaktadır. Bu bakımdan sözlü tarih çalışmaları herhangi bir olayın özellikle eğitim çatısı altında incelenmesi aşamasında öğretmen-öğrenci işbirliği sürecini daha etkin kılabilmektedir (Sarı, 2007, 42). Öğrenciler derslerde, sözlü tarih etkinliklerine katılarak birer tarihçi gibi davranabilme ve araştırma yapabilme becerileri kazanmaktadırlar (Avcı Akçalı ve Aslan, 2012, 679). Yüksek tarih bilinci ile yetişen bireyler de toplumsal hayat içinde daha bilinçli bir şekilde rol almaktadırlar.

Sosyal bilgiler dersi, sözlü tarihle olan yakın ilişkisi dolayısıyla bireysel ve toplumsal gelişime yön veren ve destek olan önemli derslerden biridir. Bu nedenle sözlü tarihe ilişkin bireylerin tutumlarının ve yaklaşımlarının ortaya çıkarılması da ilgili alan literatürü için önemli görülmektedir. 


\section{Araştırmanın Amacı}

Bu araştırmanın amacı Sosyal bilgiler öğretmen adaylarının sözlü tarih çalışmalarına yönelik tutumlarını ortaya koymaktır. Araştırmanın problemi 'Sosyal Bilgiler Öğretmen Adaylarının Sözlü Tarih Çalışmalarına Yönelik Tutumları ne düzeydedir?'

Araştırmanın alt problemleri ise Sözlü tarih çalışmalarına yönelik tutumlar;

1. Ne düzeydedir?

2. Cinsiyete göre farklılaşmakta mıdır?

3. Sınıf düzeyine göre farklılaşmakta mıdır?

4. Mezun olunan liseye göre farklılaşmakta mıdır?

5. Tarihi roman okuma durumuna göre farklılaşmakta mıdır? şeklindedir.

\section{YÖNTEM}

Araştırmanın modeli, evren ve örneklemi, veri toplama araçları ve veri analiz yöntemi bu bölümde açıklanmıştır.

\section{Araştırmanın Modeli}

Araştırma Sosyal Bilgiler öğretmen adaylarının sözlü tarih çalışmalarına yönelik tutumlarını ortaya koyma amacını taşımaktadır. Araştırmanın amacına uygun olarak veri toplama sürecinde nicel araştırma deseni olan tarama modelinden yararlanılmıştır. Tarama modelleri, geçmişte ya da halen var olan bir durumu, var olduğu şekliyle betimlemeyi amaçlayan araştırma yaklaşımlarıdır (Karasar, 2008, 77).

\section{Evren ve Örneklem}

Araştırmanın evrenini bir devlet üniversitesinde Sosyal Bilgiler Öğretmenliği lisans programında öğrenimine devam etmekte olan öğretmen adayları oluşturmaktadır. Araştırmanın örneklemini ise ilgili programda öğrenim gören ve tesadüfi olarak seçilen, araştırmaya katılmaya gönüllü olan 158 öğretmen adayı oluşturmaktadır. 8 öğretmen adayı ölçeklerini tam doldurmadığı için bu ölçekler işlem dışı bırakıldığından, kalan 150 öğretmen adayı araştırmanın örneklem grubunu temsil etmektedir.

Tablo 1.

Katılımcıların Değişkenlere Göre Dağııımı

\begin{tabular}{lcc}
\hline Cinsiyet & f & \% \\
\hline Kız & 98 & 65,3 \\
\hline Erkek & 52 & 34,7 \\
\hline Sınıf Düzeyi & & 37,3 \\
\hline $1 . \quad$ sınıf & 56 & 30,0 \\
\hline 2. sınıf & 45 & 22,7 \\
\hline 3. sınıf & 34 & 10,0 \\
\hline Mezun olunan lise & 15 & \\
\hline Düz lise & & 23,3 \\
\hline Meslek lisesi & 35 & 20,7 \\
\hline Anadolu lisesi & 31 & 46,0 \\
\hline Imam hatip lisesi & 69 & 10,0 \\
\hline Tarihi roman okuma & 15 & 52,0 \\
\hline Okudum & & 48,0 \\
\hline Okumadım & 78 & 100,0 \\
\hline Toplam & 72 & \\
\hline
\end{tabular}


Tablo 1'de görüldüğü gibi çalışma grubu 98'i kız (\% 65,3), 52'si erkek (\% 34,7) olmak üzere toplam 150 öğretmen adayından oluşmaktadır. Öğretmen adaylarının 56 'sı 1. sınıf (\% $37,3), 45^{\prime} i$ 2. Sınıf $(\% 30,0), 34^{\prime} \ddot{u}(\% 22,7) 3$. Sınıf, $15^{\prime} i(\% 10,0)$ ise 4 . Sınıf düzeyinde öğrenim görmektedir. Öğretmen adaylarının 35'i düz lise (\% 23,3), 31'i meslek lisesi (\%20,7), 69'u Anadolu lisesi $(\% 46,0), 15^{\prime} \mathrm{i}$ imam hatip $(\% 10,0)$ lise türünde mezun olmuştur. Öğretmen adaylarının $78^{\prime} i$ tarihi roman okuma $(\% 52,0)$ sorusuna olumlu cevap verirken, 72 'si ise $(\% 48,0)$ olumsuz cevap vermiştir.

\section{Veri Toplama Araçları}

Araştırmada veri toplama aracı olarak araştırmacı tarafından hazırlanmış olan kişisel bilgileri içeren form ve 'Sözlü Tarih Çalışmalarına Yönelik Tutum Ölçeği' kullanılmıştır. Kişisel bilgi formunda öğretmen adaylarının, cinsiyeti, sınıf düzeyi ve tarihi roman okuma-film izleme durumu değişkenlerine ilişkin sorulara yer verilmiştir. Öğretmen adaylarının sözlü tarih çalışmalarına yönelik tutumlarına ilişkin bilgilere ulaşmak için ise Akbaba ver Kılcan (2012) tarafından geliştirilen 'Sözlü Tarih Çalışmalarına Yönelik Tutum Ölçeği' kullanılmıştır. Tutum ölçeği 5'li Likert tipinde hazırlanmış olan 26 maddeden meydana gelmiştir. Ölçek 'derste kullanım' ve 'tarihsel aktarım' olmak üzere iki boyuttan oluşmaktadır. Araştırmacılar ölçek geliştirme sürecinde ilerde yapılacak olan çalışmalarda tekrar güvenirlik analizi yapılmasını tavsiye etmişlerdir. Bu bakımdan yapılan analiz sonucunda ölçeğin genel Cronbach Alpha katsayısı 0.90 bulunurken; derste kullanım boyutunun Cronbach Alpha katayısı 0.90; tarihsel aktarım boyutunun Cronbach Alpha katsayısı ise 0.91 bulunmuştur.

\section{Verilerin Analizi}

Araştırmanın verileri SPSS Paket Programı kullanılarak analiz edilmiştir. Verilerin parametrik testlerin genel koşullarını sağlayıp sağlamadığı kontrol edilmiştir. Verilerin normal dağılım gösterip göstermediğine Kolmogorov Smirnov testi ile bakılmıştır. Veri setlerinin normal dağıldığı (Kolmogorov Smirnov testinde derste kullanım boyutu (KSW=.622, p>0.05), kültürel aktarım boyutu ( $K S W=.676, p>0.05)$, genel tutum toplamı ( $K S W=1,011, p>0.05)$ ) görülmüştür. Değişkenlere göre de normallik dağılımına bakıldığında yalnızca tarihi roman okuma değişkeninin normal dağılım gösterdiği; cinsiyette erkeklerin ( $p=0.04)$, sınıf düzeyinde 2 . sınıfların ( $p=0.00)$, mezuniyet durumlarında anadolu lisesi $(p=0.03)$ ve imam hatip lisesinin $(p=0.03)$ normal dağılım göstermediği anlaşılmıştır.

Verilerin analizi kısmında betimsel analizler için frekans, yüzde; parametrik olan veriler için $t$ testi; parametrik olmayanlar için Kruskal Wallis ve Mann Whitney $U$ testlerinden yararlanılmıştır. Verilerin analizinde anlamlılık düzeyi 0.05 kabul edilmiştir.

\section{BULGULAR}

Bu bölümde araştırmanın amacına bağlı olarak öğretmen adaylarının sözlü tarih çalışmalarına yönelik tutumlarının çeşitli değişkenlere göre farklılaşıp farklılaşmadığına ilişkin elde edilen bulgulara yer verilmiştir.

\section{Birinci Alt Probleme iliş̧kin Bulgular ve Yorum}

Araştırmanın birinci alt probleminin analizinde öğretmen adaylarının Sözlü Tarih Çalışmalarına iliş̧kin Tutum Puanlarının düzeyi araştırılmıştır. Analiz sonuçları Tablo 2'de verilmiştir.

Tablo 2. 
Öğretmen adaylarının Sözlü Tarih Çalışmalarına Iliş̧kin Tutum Puanlarının Düzeyine ilişkin Sonuçlar

\begin{tabular}{cccccc}
\hline & $\mathbf{N}$ & Min. & Max. & $\overline{\mathrm{X}}$ & Ss \\
\hline Derste Kullanım & 150 & 12.00 & 60.00 & 28.19 & 9,89 \\
\hline Kültürel Aktarım & 150 & 25.00 & 70.00 & 49.38 & 10.64 \\
\hline $\begin{array}{c}\text { Tutum Toplam } \\
\text { Puan }\end{array}$ & 150 & 52.00 & 119.00 & 77.57 & 10.57 \\
\hline
\end{tabular}

Tablo 2 incelendiğinde sosyal bilgiler öğretmen adaylarının sözlü tarih çalışmalarına yönelik tutumlarının orta düzeyde olduğu görülmektedir ( $\overline{\mathrm{X}}=77.57$ ). Bu sonuca göre öğretmen adaylarının sözlü tarih çalışmalarına ilişkin daha fazla bilgi ve etkinliğe ihtiyaç duydukları söylenebilir.

\section{İkinci Alt Probleme ilişkin Bulgular ve Yorum}

Araştırmanın ikinci alt probleminin analizinde öğretmen adaylarının Sözlü Tarih Çalışmalarına ilişkin Tutum Puanlarının Cinsiyet Değişkenine göre farklılaşıp farklılaşmadığı araştırılmıştır. Analiz sonuçları Tablo 3'te verilmiştir.

Tablo 3.

Öğretmen adaylarının Sözlü Tarih Çalışmalarına Iliş̧in Tutum Puanlarının Cinsiyet Değişkenine Göre Mann Whitney U Testi Sonuçları

\begin{tabular}{|c|c|c|c|c|c|c|}
\hline Boyutlar & Cinsiyet & $\mathbf{N}$ & $\begin{array}{c}\text { Ortalama } \\
\text { Farkı }\end{array}$ & $\begin{array}{c}\text { Toplam } \\
\text { Farkı }\end{array}$ & $\begin{array}{c}\text { Mann } \\
\text { Whitney U }\end{array}$ & $p$ \\
\hline \multirow{2}{*}{$\begin{array}{c}\text { Derste } \\
\text { Kullanım }\end{array}$} & $\mathrm{KIZ}$ & 98 & 78.64 & 7707.00 & \multirow[t]{2}{*}{2240.000} & \multirow[t]{2}{*}{0,22} \\
\hline & Erkek & 52 & 69.58 & 36.18 & & \\
\hline \multirow{2}{*}{$\begin{array}{l}\text { Tarihsel } \\
\text { Aktarım }\end{array}$} & $\mathrm{K} I \mathrm{Z}$ & 98 & 69.59 & 6820.00 & \multirow[t]{2}{*}{1969.000} & \multirow[t]{2}{*}{$0,02^{*}$} \\
\hline & Erkek & 52 & 86.63 & 4505.00 & & \\
\hline \multirow{2}{*}{$\begin{array}{c}\text { Tutum } \\
\text { Toplam } \\
\text { puan }\end{array}$} & $\mathrm{KIz}$ & 98 & 72.81 & 7135.00 & \multirow[t]{2}{*}{2284.000} & \multirow[t]{2}{*}{0,30} \\
\hline & Erkek & 52 & 80.58 & 4190.00 & & \\
\hline
\end{tabular}

Tablo 3 incelendiğinde öğretmen adaylarının sözlü tarih çalışmalarına ilişkin tutumlarını cinsiyetlerine göre Tarihsel aktarım boyutunda anlamlı olarak farklılaştığı ve bu farklılığın erkekler lehine olduğu görülmektedir. $(p<0.05)$ Bu bulguya dayanarak, sözlü tarih çalışmalarına dayalı etkinliklerde kültürel etkileşim ve geçmişten bugüne bilgi aktarımı konularında erkeklerin daha olumlu düşündükleri söylenebilir.

Analiz sonucunda derste kullanım alt boyutu ve tutum toplam puanlarının cinsiyete göre farklılaşmadığı belirlenmiştir.

\section{Üçüncü Alt Probleme İlişkin Bulgular ve Yorum}

Araştırmanın üçüncü alt probleminin analizinde öğretmen adaylarının Sözlü Tarih Çalışmalarına illişkin Tutum Puanlarının sınıf düzeyine göre değişimi araştırılmıştır. Analiz sonuçları Tablo 4'te verilmiştir.

Tablo 4. 
Öğretmen adaylarının Sözlü Tarih Çalışmalarına Iliş̧kin Tutum Puanlarının Sınıf Değişkenine Göre Kruskal Wallis Sonuçları

\begin{tabular}{|c|c|c|c|c|c|c|}
\hline Sınıf Düzeyi & \multirow{5}{*}{$\begin{array}{c}\text { Derste } \\
\text { Kullanım }\end{array}$} & $\mathbf{N}$ & Ortalama & Ki-Kare & df & $\mathbf{p}$ \\
\hline 1. Sinif & & 56 & 74.46 & \multirow{4}{*}{0,335} & \multirow{4}{*}{3} & \multirow{4}{*}{0,95} \\
\hline 2. Sinif & & 45 & 77.79 & & & \\
\hline 3. Sinıf & & 34 & 76.22 & & & \\
\hline 4. Sinif & & 15 & 70.90 & & & \\
\hline 1. Sinıf & \multirow{4}{*}{$\begin{array}{l}\text { Kültürel } \\
\text { Aktarım }\end{array}$} & 56 & 72.53 & \multirow{4}{*}{0,794} & \multirow{4}{*}{3} & \multirow{4}{*}{0,85} \\
\hline 2. Sinif & & 45 & 76.33 & & & \\
\hline 3. Sinif & & 34 & 75.75 & & & \\
\hline 4. Sinif & & 15 & 83.53 & & & \\
\hline 1. Sinif & \multirow{4}{*}{$\begin{array}{l}\text { Tutum } \\
\text { Toplam } \\
\text { Puan }\end{array}$} & 56 & 72.09 & \multirow{4}{*}{0,722} & \multirow{4}{*}{3} & \multirow{4}{*}{0,87} \\
\hline 2. Sinif & & 45 & 75.79 & & & \\
\hline 3. Sinıf & & 34 & 78.41 & & & \\
\hline 4. Sinıf & & 15 & 80.77 & & & \\
\hline
\end{tabular}

Tablo 4 incelendiğinde öğretmen adaylarının sözlü tarih çalışmalarına ilişkin tutumlarının sınıf düzeylerine göre anlamlı bir düzeyde farklılaşmadığı görülmektedir. ( $p>0.05)$

\section{Dördüncü Alt Probleme Iliş̧kin Bulgular ve Yorum}

Araştırmanın dördüncü alt probleminin analizinde öğretmen adaylarının Sözlü Tarih Çalışmalarına İlişkin Tutum Puanlarının mezun olunan lise Değişkeni açısından değişimi araştırılmıştır. Analiz sonuçları Tablo 5'te verilmiştir.

Tablo 5.

Öğretmen adaylarının Sözlü Tarih Çalışmalarına Iliş̧kin Tutum Puanlarının Mezun olunan lise Değişkenine Göre Kruskal Wallis Sonuçları

\begin{tabular}{|c|c|c|c|c|c|c|}
\hline Mezun Olunan Lise & & $\mathbf{N}$ & $\begin{array}{c}\text { Ortalama } \\
\text { Sırası }\end{array}$ & Ki-Kare & df & $p$ \\
\hline Düz Lise & \multirow{4}{*}{$\begin{array}{c}\text { Derste } \\
\text { Kullanım }\end{array}$} & 35 & 77.10 & & & \\
\hline Meslek Lisesi & & 31 & 72.15 & & & \\
\hline Anadolu Lisesi & & 69 & 77.30 & 0,555 & 3 & 0,91 \\
\hline İmam Hatip Lisesi & & 15 & 70.43 & & & \\
\hline Düz Lise & \multirow{4}{*}{$\begin{array}{l}\text { Kültürel } \\
\text { Aktarım }\end{array}$} & 35 & 70.56 & \multirow{4}{*}{2,479} & & \multirow{4}{*}{0,48} \\
\hline Meslek Lisesi & & 31 & 78.21 & & \multirow{3}{*}{3} & \\
\hline Anadolu Lisesi & & 69 & 73.55 & & & \\
\hline İmam Hatip Lisesi & & 15 & 90.40 & & & \\
\hline Düz Lise & \multirow{4}{*}{$\begin{array}{c}\text { Tutum } \\
\text { Toplam } \\
\text { Puan }\end{array}$} & 35 & 71.97 & \multirow{4}{*}{$, 1,780$} & \multirow{4}{*}{3} & \multirow{4}{*}{0,62} \\
\hline Meslek Lisesi & & 31 & 76.81 & & & \\
\hline Anadolu Lisesi & & 69 & 73.80 & & & \\
\hline İmam Hatip Lisesi & & 15 & 88.83 & & & \\
\hline
\end{tabular}

Tablo 5 incelendiği zaman öğretmen adaylarının sözlü tarih çalışmalarına ilişkin tutumları ve mezun olunan lise değişkeni arasında anlamlı düzeyde bir farklılığa rastlanılmamıştır. $(P>0.05)$ 


\section{Beşinci Alt Probleme İlişkin Bulgular ve Yorum}

Araştırmanın beşinci alt probleminin analizinde öğretmen adaylarının Sözlü Tarih Çalışmalarına îlişkin Tutum Puanlarının Tarihi roman okuma değişkeni açısından değişimi araştırılmıştır. Analiz sonuçları Tablo 6'da verilmiştir.

Tablo 6.

Öğretmen adaylarının Sözlü Tarih Çalışmalarına Ilişskin Tutum Puanlarının Tarihi roman okuma Değişkenine Göre t-Testi Sonuçları

\begin{tabular}{|c|c|c|c|c|c|c|c|}
\hline & $\begin{array}{l}\text { Tarihi } \\
\text { roman }\end{array}$ & $\mathbf{N}$ & $\overline{\mathrm{x}}$ & $S$ & sd & $t$ & $\mathbf{P}$ \\
\hline \multirow{2}{*}{$\begin{array}{l}\text { Derste } \\
\text { Kullanım }\end{array}$} & Okudum & 78 & 29,31 & 9,73 & \multirow{6}{*}{148} & \multirow[t]{2}{*}{1,44} & \multirow[t]{2}{*}{0,15} \\
\hline & Okumadım & 72 & 26,99 & 9,98 & & & \\
\hline \multirow{2}{*}{$\begin{array}{l}\text { Tarihsel } \\
\text { Aktarım }\end{array}$} & Okudum & 78 & 49,97 & 10,75 & & \multirow[t]{2}{*}{,- 64} & \multirow[t]{2}{*}{$0,01^{*}$} \\
\hline & Okumadım & 72 & 48,83 & 10,56 & & & \\
\hline \multirow{2}{*}{$\begin{array}{l}\text { Tutum Toplam } \\
\text { puan }\end{array}$} & Okudum & 78 & 78,14 & 11,51 & & \multirow[t]{2}{*}{0,68} & \multirow[t]{2}{*}{0,49} \\
\hline & Okumadım & 72 & 76,96 & 9,48 & & & \\
\hline
\end{tabular}

Tablo 6 incelendiği zaman öğretmen adaylarının sözlü tarih çalışmalarına ilişkin tutumları ve Tarihi roman okuma değişkeni arasında, Tarihsel aktarım boyutu açısından arasında anlamlı düzeyde bir farklılık olduğu görülmektedir $(t(148)=-, 64 ; p<0,05)$.

Öğretmen adaylarının tutum puan ortalamaları incelendiğinde bu farklılı̆ı̆n tarihi roman okuduğunu belirtenler lehine olduğu görülmektedir ( $\overline{\mathrm{X}}=49,97)$. Bu bulguya dayanarak, sözlü tarih çalışmalarında tarihi roman okumanın çalışma sürecine olumlu etkilerinin olabileceği söylenebilmektedir.

Analiz sonucunda Derste kullanım alt boyutu ve tutum toplam puanlarının tarihi roman okuma değişkenine göre anlamlı bir farklılık içermediği belirlenmiştir.

\section{SONUÇ, TARTIŞMA VE ÖNERILER}

Bu çalışmada, Sosyal Bilgiler öğretmen adaylarının sözlü tarih çalışmalarına ilişkin tutumlarını ortaya koymak amaçlanmıştır. Bu amaç doğrultusunda tarama yöntemi ile Sözlü Tarih Çalışmalarına Yönelik Tutum Ölçeği katılımcı öğretmen adaylarına uygulanmıştır. Elde edilen verilerin analizi sonucunda, öğretmen adaylarının sözlü tarih çalışmalarına yönelik genel tutumlarının cinsiyet değişkenine göre bir farklılık göstermediği anlaşılmıştır. Bu sonuç daha önce yapılmış olan Akbaba ve Kılcan (2014)'nın çalışmasının sonuçları ile uyumludur. Sözlü tarih puanlarının alt boyutları açısından cinsiyet değişkenin durumu incelendiğinde ise 'tarihsel aktarım' boyutunda erkeklerin olumlu bir tutuma sahip olduğu dikkat çekmektedir. Öğretmen adaylarının sözlü tarih çalışmalarına ilişkin tutumlarının öğrenim gördükleri sınıf düzeyine göre ve mezun oldukları lise türüne göre herhangi bir farklılık içermediği de araştırmanın diğer sonuçları arasında yer almaktadır (Akbaba ve Kılcan, 2014). Sosyal bilgiler öğretmen adaylarının sözlü tarih çalışmalarına yönelik tutumlarının tarihi olayları, durumları içeren roman okumafilm izleme değişkeni açısından yalnızca 'tarihsel aktarım' boyutunda anlamlı bir farklığının olduğu görülmüştür. Sosyal bilgiler dersi için, sözlü tarih çalışmalarında tarihsel aktarım boyutunun değişim ve süreklilik ve kültürel aktarım ile doğrudan ilişkisinin olduğu açıktır. Sözlü tarih yardımıyla geçmişle bugün arasında bir köprü kuran bireyler, bundan sonra toplumsal yapı içinde daha kendinden emin ve daha sosyal bir kişi olarak var olabilecektir. Bu sonucun 
Demircioğlu, (2005), Deveci (2009), İncegül'ün (2010) araştırma sonuçlarıyla benzerlik gösterdiği anlaşılmıştır.

Araştırmanın sonuçları kapsamında,

- Başta öğretmenler olmak üzere tüm eğitimcilerin ve öğrencilerin sözlü tarihi tam anlamıyla kavrayabilmesi ve etkili şekilde yararlanabilmesi için eğitici etkinlikler, seminerler düzenlenmesi,

- Tarih bilinci kazanma ve tarihsel empati kurabilmeyi öğrenebilmek için sözlü tarih çalışmalarından yararlanılması,

- Lisans öğrenimi süresince okul içi ve dışında sözlü tarih çalışmaları, proje ödevlerinin verilip, grupla çalışmanın desteklenmesi,

- Sözlü tarih açısından değişim ve sürekliliği anlamak için tarihi romanların tavsiye edilmesi, ilgili görülen tarihi filmlerin izletilmesi,

- Kongre ve sempozyum gibi önemi tartışma platformlarında sözlü tarihin yeri, önemi, etkili kullanımı konularının tartışılması,

- Ilgili alan literatürünü geliştirmek adına tez ve makalelerde sözlü tarih etkinliklerine daha çok yer verilmesi önerilmektedir.

\section{KAYNAKLAR}

Akbaba, B., Kılcan, B. (2012). Sözlü Tarih Çalışmalarına Yönelik Tutum Ölçeğinin Geliştirilmesi: Geçerlik ve Güvenirlik Çalışmaları. Pegem Eğitim ve Öğretim Dergisi, 2(1), ss. 1-10.

Akbaba, B., Kılcan, B. (2014). Sosyal Bilgiler Öğretmen Adaylarının Sözlü Tarih Çalışmalarına Yönelik Tutumları. Illköğretim Online, 13(3), ss. 746-758.

Avcı Akçalı, A., Aslan, E. (2012). Tarih Öğretiminin İyileştirilmesi Yolunda Alternatif Bir Yöntem: Sözlü Tarih. Kastamonu Eğitim Dergisi, 20(2), ss. 669-688.

Çaykent, Ö. (2015). Sözlü Tarih. Ahmet Şimşek (Ed.) Tarih İçin Metodoloji. Ankara: Pegem Akademi.

Çengelci, T. (2012). Sosyal Bilgiler Öğretim Programında Somut Olmayan Kültürel Mirasın Yeri. Uludağ Üniversitesi Eğitim Fakültesi Dergisi, 25(1), ss. 185-2013.

Demircioğlu, i. H. (2005). Sözlü Tarihin Bir Öğretim Yaklaşımı Olarak Tarih Derslerinde Kullanımı. Il. Sosyal Bilimler Eğitimi Kongresi, ss. 310-315.

Deveci, H. (2009). Sosyal Bilgiler Dersinde Kültürden Yararlanma: Öğretmen Adaylarının Kültür Portfolyolarının İncelenmesi. Electronic Journal of Social Sciences, 8(28), ss. 1-19.

Hoopes, J. (1979). Oral History An Introduction for Students. The University of North Carolina Press.

İncegül, S. (2010). Sosyal Bilgiler Dersinde Örnek Bir Sözlü Tarih Uygulaması. (Yayınlanmamış Yüksek Lisans tezi). Marmara Üniversitesi Eğitim Bilimleri Enstitüsü, İstanbul.

Kabapınar, Y., İncegül , S. (2016). Değişim Ve Süreklilik Bağlamında Oyun Ve Oyuncağa Bakmak: Bir Sözlü Tarih Çalışması. Turkish History Education Journal, 5(1), ss. 74-96.

Kabapınar, Y. (2016). Kuramdan Uygulamaya Hayat Bilgisi ve Sosyal Bilgiler Öğretimi. Genişletilmiş 5. Baskı. Ankara: Pegem Akademi.

Karasar, N. (2008), Bilimsel Araştırma Yöntemi. Ankara: Nobel Yayın Dağıtım. 
Küpüç, E. (2014). Sözlü Tarih Kavramı Ve Sözlü Tarihin Tarih Öğretimindeki Rolü. (Yayınlanmamış Yüksek Lisans tezi). Yüzüncü Yıl Üniversitesi Eğitim Bilimleri Enstitüsü, Van.

Özer, E. (2012). Sosyal Bilgiler Dersinde Yerel Ve Sözlü Tarih Etkinliklerinin Programlanması (Yayınlanmamış Yüksek Lisans tezi). Konya Üniversitesi Eğitim Bilimleri Enstitüsü, Konya.

Öztürk, S. (2010). Türkiye'de Sözlü Tarihten Iletişim Araştırmalarında Yararlanma Üzerine Notlar. Milli Folklor, 22(87), ss. 13-26.

Portelli, A. (2009). What Makes Oral History Different. Luisa Del Giudice (Ed. ). Oral History, Oral Culture and Italian Americans. First Edition. United States: Palgrave Macmillan.

Ritchie, Donald, A. (2015). Doing Oral History. Third Edition. Oxford University Press.

Sarı, i. (2007). Sosyal bilgiler öğretiminde sözlü tarih etkinliklerinin öğrenci başarı ve tutumlarına etkisi (Yayınlanmamış doktora tezi). Gazi Üniversitesi Eğitim Bilimleri Enstitüsü, Ankara.

Thompson, P., Bornat, J. (2017). The Voice of The Past Oral History. Fourth Edition. Oxford University Press.

Tokmak, M. (2016). Sözlü Tarih ve Derinlemesine Görüşme. Ardahan Üniversitesi iktisadi ve idari Bilimler Fakültesi Dergisi, Sayı 3, ss. 83-98.

Ulusoy, K. (2011). Türk Toplum Hayatında Yaşatılan Kahve Ve Kahvehane Kültürü. Milli Folklor, 23(80), ss. 159-169.

Yow, Valerie, R. (2015). Recording Oral History A Guide fort he Humanities and Social Sciences. Third Edition. Rowman \& Littlefield. 


\begin{abstract}
SUMMARY
In our day; view of individuals to social life has changed at the focus of scientific and technological advances. At the latest years; conducting link between past-today-future has gained importance associate with concentric improvement of education together with scientific advances. Belonging to society by history consciousness is important addition to being social individual in communal life. Having a good command on society's historical and taking lesson from the past are seen so precious to get on future more confidentially. At the latest period; different method and techniques have come to prominence by adopting more modern approaches regarding education process. At this point; one of this different and new is 'Oral History'. Fundamentally oral history is a method that is applied together with local history studies. Even though it is not new idea for education world; especially studies which can contribute to related field literature have increased nowadays. Oral history contains to get deep information about a specific topic by referring documents and proofs, analyzing individuals' history and past experiences. In this getting information process; interview technique that is done by voice record devices is one of the essential parts. Historical study related with any topic van be done by getting by on every event that is lived in historical process is valuable. Oral history studies can take place in education programs because it is helpful also for social science lesson. Oral history studies get attracts at the point of improving social consciousness; respect to cultural heritage and transmission of oral culture from past to today in terms of sustainability in social studies lessons. For that reason, social science lesson that has important mission for cultural continuity also cares oral history studies. Oral history improves both individual development both team cooperation in working process associated by using in education process. Aim of this research is to put forward attitudes of social science teacher candidates regarding oral history studies. Working group of research is 150 teacher candidates who continues Social Studies Teacher Undergraduate Program in West Karadeniz region. Data is gathered by "Attitude Scale regarding Oral History Studies" to put forward attitudes of social studies teacher candidates regarding oral history studies. Used attitude scale in research consists of two fundamental dimensions as use in the lesson and historical transmission. In the data gathering process, it is benefitted from quantitative searching design screening model. Collected data is analyzed by SPPS packet program. According to findings; it is seen that there is positive circumstance in countenance male teacher candidates at historical transmission point in attitudes of social studies teacher candidates regarding oral history studies. Moreover; it remarks that candidates who read historical book have more positive attitude. Any difference in attitudes of teacher candidates regarding oral history isn't observed depends on class level. Being a guide is important for teacher candidates who will be teacher of future to transmit culture in social science lesson and conduct a relation from past to today. For that reason, giving more place to oral history studies and activities during undergraduate education process can be recommended. So, it is thought that teacher candidates would begin to work as being command on oral history studies.
\end{abstract}

